\title{
Produção de arroz orgânico em assentamentos rurais no Rio Grande do Sul: práticas de organização coletiva e sua contribuição para a fixação do homem no campo
}

\author{
Organic rice production in rural settlements in Rio Grande do Sul: \\ collective organization practices and their contribution to the fixation \\ of man in the field
}

\author{
Michele Lindner'(i), Rosa Maria Vieira Medeiros ${ }^{1(1)}$ \\ ' UFRGS, Departamento de Geografia, Porto Alegre, RS, Brasil
}

\section{RESUMO}

Ao analisarmos temáticas referentes à reforma agrária, a luta e a permanência na terra representam temas de grandes inquietações. Isto porque ser assentado não garante as plenas condições de produção. Assim, a luta é constante e diversas vezes, torna-se necessário que se busquem alternativas a uma produção convencional. Nesse contexto, o artigo busca abordar a produção de arroz orgânico em assentamentos rurais no Rio Grande do Sul, desde sua organização inicial, até os mecanismos que fazem com que atualmente esta seja a maior experiência em produção de arroz orgânico da América Latina. $O$ histórico do desenvolvimento da cadeia produtiva tem demonstrado que a experiência tem grande importância para o desenvolvimento socioeconômico, trazendo inúmeros benefícios para as famílias de assentados envolvidos.

Palavras-chave: assentamentos; arroz; produção orgânica

\begin{abstract}
When analyzing themes related to land reform, the struggle and the permanence on land represent themes of great concern. This is because being seated does not guarantee full production conditions. Thus, the struggle is constant and several times, it becomes necessary to seek alternatives to conventional production. In this context, the article seeks to address the production of organic rice in rural settlements in Rio Grande do Sul, from its initial organization, to the mechanisms that make it currently the greatest experience in organic rice production in Latin America. The history of the development of the production chain has shown that the experience is of major importance for socioeconomic development, bringing countless benefits to the families of settlers involved.
\end{abstract}

Keywords: settlements; rice; organic production 


\section{INTRODUÇÃO}

A necessidade de entender as dinâmicas e alternativas encontradas pelos produtores em assentamentos rurais para manter a reprodução socioeconômica, vem das desigualdades encontradas no campo brasileiro. Essas desigualdades não se limitam ao acesso à terra, a falta de recursos para desenvolver e manter a produção são grandes entraves para a fixação do homem na terra. Nesse contexto, este artigo busca abordar uma experiência exitosa, entre outras, do desenvolvimento de produções alternativas em assentamentos rurais no Rio Grande do Sul (RS), a produção de arroz orgânico, desenvolvida por grupos de assentados em algumas regiões do estado.

É sabido que o problema da concentração de terras no Brasil possuí raízes histórico/geográficas. Desde a ocupação europeia, percebe-se que a distribuição de terras não se deu de forma igualitária e sustentável. Silva (1996), ao analisar a relação entre proprietários de terras e o Estado na compreensão da sociedade brasileira chama a atenção para que a "alta concentração da propriedade da terra é um fator em torno do qual evoluiu e evolui a 'questão da terra' e que atravessa todos os períodos da nossa história" (SILVA, 1996, p.13).

O latifúndio no Brasil tem início em 1530 com a criação das capitanias hereditárias e o sistema de sesmarias. Essa concentração é agravada com a Lei de Terras de 1850, que ao proibir a ocupação de terras públicas, determinando que a aquisição poderia se dar apenas mediante pagamento em dinheiro, reforça mais uma vez o poder dos latifundiários tornando ilegal a posse dos pequenos produtores. A abolição da escravatura e instauração da República também não mudaram esse quadro, que começa a ser debatido apenas em fins dos anos 1950 e início dos anos 1960 com a industrialização brasileira (INCRA, 2020-a).

A necessidade de se pensar em redistribuição de terras passa a ser evidenciada com o agravamento do clima de insatisfação no campo brasileiro e o temor da eclosão de uma revolução camponesa. Esse contexto, leva a articulação 
da primeira proposta de reforma agrária por um governo no Brasil através do Estatuto da Terra. O Estatuto da Terra foi criado pela lei 4.504, de 30/11/1964, sendo, portanto, uma obra do regime militar que acabava de ser instaurado no país através do golpe militar de 31/03/1964, e tinha como metas básicas o desenvolvimento da agricultura e a execução da reforma agrária. O Estatuto da Terra deu soluções técnicas para a questão agrária, removendo obstáculos legais e instituindo desapropriações através de títulos da dívida pública, porém gerou ações pontuais insuficientes para transformar a estrutura fundiária brasileira.

No final da década de 1970 as contradições do modelo agrícola se tornam mais intensas e começam a surgir ocupações de terras. De acordo com Fernandes (2000), os últimos anos desta década representam um marco histórico da luta pela terra.

A expropriação, a expulsão das famílias camponesas e a usurpação do território indígena geraram uma das condições que levaram à luta os camponeses que iriam realizar a ocupação de terra, que também inaugurou o processo de formação do MST na região noroeste rio-grandense (FERNANDES, 2000, p.50).

A expulsão de 1.800 famílias de colonos da Reserva Indígena Nonoai por índios Kaigang no mês de maio de 1978, representou o início do processo de luta pela terra no estado do Rio Grande do Sul RS. A essas famílias de colonos que o governo do estado havia concedido a permissão de ocupar a área indígena, há cerca de 15 anos, na condição de rendeiros do Serviço de Proteção ao Índio (SPI) só restaram três alternativas: "1) migrar para os projetos de colonização da Amazônia; 2) tornar-se assalariados de empresas agropecuárias ou de indústrias, migrando para as cidades; 3) lutar pela terra no Estado do Rio Grande do Sul" (FERNANDES, 2000, p. 51).

Assim, os anos 1980 representaram uma década de intensa luta pela terra, com diversas ocupações e manifestações organizadas pelo então formado Movimento dos Trabalhadores Rurais Sem Terra (MST). Da mesma forma que as ações aconteceram, a repressão policial também se acentuou e o movimento 
passou a ter visibilidade da mídia e da sociedade em geral, ocorrendo as primeiras conquistas, a criação dos assentamentos (FERNANDES, 2000).

Contudo, o acesso à terra por si só não trouxe soluções concretas para os agricultores assentados, que em diversos casos passaram a enfrentar outros desafios, relacionados a permanência na terra e a produção de alimentos. Devido a inúmeras dificuldades no processo de adaptação aos modos de produção tradicionais, seja pela falta de recursos, seja pelo escasso conhecimento técnico, surgiram novas alternativas de produção, focadas em experiências sustentáveis capazes de propiciar a inclusão socioeconômica dos produtores assentados.

Dessa forma, as informações aqui apresentadas buscam demonstrar como ocorreu a implantação e o desenvolvimento dessa prática produtiva a partir de materiais bibliográficos, informações fornecidas pela Cooperativa Central dos Assentamentos do Rio Grande do Sul (COCEARGS) e entrevistas com técnicos da Certificação Participativa da COCEARGS, produtores assentados ligados ao Grupo Gestor do Arroz Ecológico (GGAE) e lideranças do MST do estado do Rio Grande do Sul.

Assim, o artigo se organiza a partir de uma contextualização da experiência da produção do arroz orgânico e as relações com a agroecologia, a organização dos assentados e a expansão da produção.

\section{AGROECOLOGIA E O ARROZ ORGÂNICO NO RIO GRANDE DO SUL}

Os primeiros assentamentos de reforma agrária no estado do Rio Grande do Sul foram criados na década de 1980. No período entre 1986 e 1990, foram criados os primeiros assentamentos 13 assentamentos (Tabela 1), localizados na metade norte do estado, nas Regiões Intermediárias de Ijuí, Passo Fundo, Santa Maria e Porto Alegre. 
Tabela 1 - Assentamentos criados no Rio Grande do Sul entre 1986 e 2020

\begin{tabular}{lccccc}
\hline \multirow{2}{*}{ Regiões Intermediárias do RS } & \multicolumn{5}{c}{ Assentamentos } \\
& $\mathbf{1 9 8 6 - 1 9 9 0}$ & $\mathbf{1 9 9 1 - 2 0 0 0}$ & $\mathbf{2 0 0 1 - 2 0 1 0}$ & $\mathbf{2 0 1 1 - 2 0 2 0}$ & Total \\
\hline ljuí & 2 & 21 & 16 & 1 & $\mathbf{4 0}$ \\
Passo Fundo & 6 & 33 & 26 & 1 & $\mathbf{6 6}$ \\
Caxias do Sul & - & 4 & 5 & 1 & $\mathbf{1 0}$ \\
Uruguaiana & - & 21 & 20 & 1 & $\mathbf{4 2}$ \\
Santa Maria & 3 & 15 & 11 & 2 & $\mathbf{3 1}$ \\
Porto Alegre & 2 & 18 & 5 & 2 & $\mathbf{2 7}$ \\
Santa Cruz - Lajeado & - & 6 & 1 & 2 & $\mathbf{9}$ \\
Pelotas & - & 82 & 34 & 2 & $\mathbf{1 1 8}$ \\
\hline Total & $\mathbf{1 3}$ & $\mathbf{2 0 0}$ & $\mathbf{1 1 8}$ & $\mathbf{1 2}$ & $\mathbf{3 4 3}$ \\
\hline
\end{tabular}

Fonte: INCRA (2020-b).

Conforme podemos perceber na Tabela 1, que mostra os assentamentos criados no estado entre 1980 e 2020, a década de 1990 representou o ápice na criação de assentamentos no estado. Foi também no final da década de 1990 que os assentados da RMPA começaram a plantar os primeiros hectares de arroz orgânico.

Essa experiência, teve início em assentamentos rurais da RMPA no ano de 1999, em caráter experimental, quando foram cultivados 7 hectares de terra em dois assentamentos. Segundo Campos e Medeiros (2014), dez anos após a experiência inicial, na safra 2009/2010, a produção de arroz orgânico já envolvia 211 famílias de oito assentamentos, que cultivaram 2.104 hectares.

As autoras explicam que a iniciativa partiu das famílias assentadas, de suas cooperativas e do MST, movimento social ao qual estão vinculadas, e suas motivações foram de ordem econômica e social (CAMPOS; MEDEIROS, 2014). No que tange a questão econômica, buscou-se produzir com menores custos em um mercado onde a concorrência fosse menos capitalizada do que no mercado de arroz convencional. Medeiros et al (2013, p.12), explica que "nos anos 2000, uma parcela significativa dessas famílias envolvidas com a produção do arroz convencional acumulava dívidas decorrentes dos altos custos de produção pelo 
uso de insumos externos, como agrotóxicos além dos baixos preços do arroz no mercado".

Nesse contexto, a agricultura orgânica representou uma opção para essas famílias de agricultores que não conseguiam se adaptar a uma agricultura convencional, devido, entre outros fatores, à falta de recursos. A agricultura orgânica, na maioria das vezes está relacionada a um estilo de agricultura que segue princípios e conceitos da agroecologia, a qual mescla os saberes tradicionais com os conhecimentos científicos em busca de produções alternativas. Candiotto, Corrijo e Oliveira (2008), salientam que diferente das formas tradicionais de agricultura, a agricultura chamada de alternativa teve seus métodos desenvolvidos a partir da constatação do impacto de técnicas e métodos convencionais.

Entre os impactos gerados pela agricultura convencional, está a degradação ambiental, a pobreza rural gerada pela concentração de terras destinadas a monoculturas, a mecanização da agricultura agravando o desemprego rural e o aumento dos minifúndios que se tornam muitas vezes espaços insuficientes para o sustento de famílias numerosas. Situações como essas, levaram muitos agricultores a ingressar na luta pela terra e após a conquista, rever a forma de produzir, buscando alternativas diferenciadas daquelas que os excluíram do processo produtivo anteriormente.

Com isso, as novas formas de agricultura sustentável vêm buscando minimizar impactos gerados pela agricultura convencional e pelo sistema de produção capitalista que visa somente a maximização da produção sem se importar com as consequências sociais e ambientais geradas por tais práticas. A produção de alimentos de forma sustentável em pequenas e médias propriedades demanda significativa mão de obra durante o processo produtivo, além de respeitar as condições locais e os saberes tradicionais.

Dessa forma, todo o processo requer além de um esforço de pesquisa, a participação dos produtores, pois são eles que vão pôr em pratica as conquistas 
da ciência. Os produtores são os agentes do processo, são eles os sujeitos capazes de operar as mudanças e consequentemente transformar suas vidas e de suas famílias.

Em assentamentos rurais, essas transformações têm sido percebidas com mais força nas últimas décadas; no entanto, Altieri (2012, p.18) chama a atenção para que não se trata de algo recente, segundo o autor, "a partir do final da década de 1990, os movimentos camponeses e rurais têm adotado a Agroecologia como bandeira de sua estratégia de desenvolvimento e soberania alimentar".

Segundo Altieri (2012), a Via Campesina acredita que está nas mãos dos pequenos produtores a proteção dos meios de vida, emprego, segurança alimentar e saúde das pessoas, por meio de mudanças no modelo agrícola industrial baseado nas grandes propriedades e no comércio voltado para exportação. Dessa forma, o autor coloca que existem quatro razões para a agroecologia ter um enfoque compatível com a agenda dos movimentos sociais:

a. A Agroecologia é socialmente mobilizadora, já que sua difusão requer a intensa participação dos agricultores;

b. Trata-se de uma abordagem culturalmente assimilável, já que se baseia nos conhecimentos tradicionais e promove um diálogo de saberes com métodos científicos modernos;

c. Promove técnicas economicamente viáveis, com ênfase no uso do conhecimento indígena, da biodiversidade agrícola e dos recursos locais, evitando assim a dependência de insumos externos;

d. A Agroecologia é ecológica per se, uma vez que evita modificar os sistemas de produção existentes, promovendo a diversidade, as sinergias, otimizando o desempenho e a eficiência do sistema produtivo (ALTIERI, 2012, p. 18-19).

Portanto, a agroecologia apresenta-se como uma noção de grande relevância para esses produtores, visto que, a produção de arroz realizada nos assentamentos estudados tem como base seus princípios. A implantação da agricultura orgânica de base ecológica implica em uma série de transformações, sobretudo nas relações sociais de produção, uma vez que exige uma participação ativa do agricultor e uma radical mudança na relação deste com o ambiente rumo a uma produção sustentável. 
Nesse contexto, o desenvolvimento das lavouras de arroz orgânico e o número de famílias envolvidas na produção vem crescendo significativamente ao longo dos anos. Isso pode ser percebido pelos dados das últimas safras, que demonstram informações referentes à área plantada (ha) no Rio Grande do Sul, conforme mostra a Figura 1.

Figura 1 - Produção de arroz orgânico em assentamentos no RS (ha)

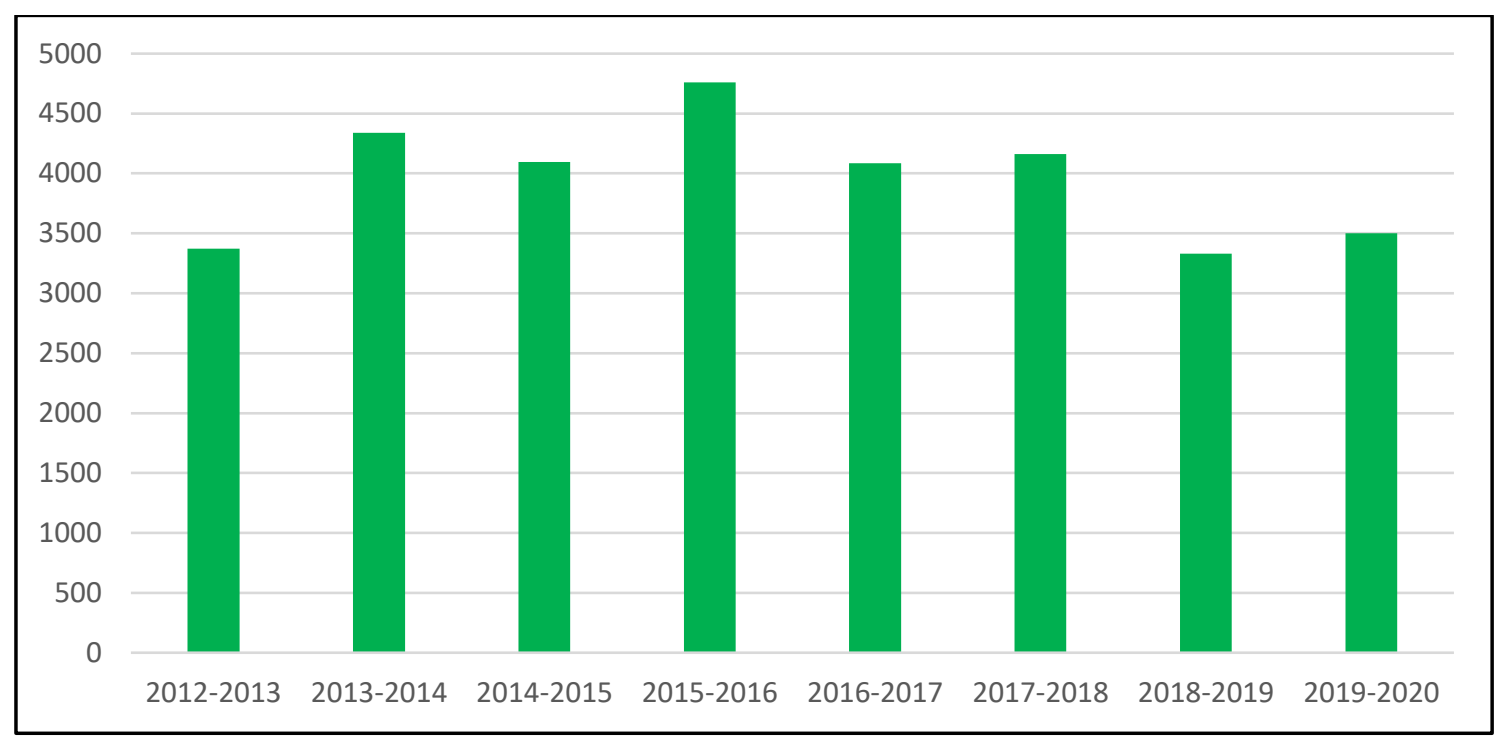

Fonte: Certificação Participativa da COCEARGS (2019).

A partir das informações, é possível perceber uma certa constância na área plantada, com algumas oscilações que acompanham momentos de crises econômicas e adversidades climáticas ocorridas nas regiões de produção. Da mesma forma, o número de famílias produtoras envolvidas na produção também vem apresentando pequenas variações, tendo contado na safra 2019-2020 com cerca de 292 famílias de produtores. A expansão da produção ao longo dos anos foi impulsionada pela criação do Grupo Gestor do Arroz Ecológico (GGAE), cuja meta além de reunir as famílias produtoras, foi promover a sistematização de dados, a troca de experiências entre os produtores, a negociação com instituições públicas e privadas, a ampliação de parcerias e a busca pelo aumento do número 
de famílias assentadas envolvidas no cultivo ecológico do arroz irrigado (MENEGON et al, 2009).

O GGAE teve início com um grupo de agricultores que plantavam arroz e começaram a se reunir para discutir as dificuldades técnicas enfrentadas nos processos produtivos, assim como buscavam equipamentos e recursos para a produção tendo como motivadora a Cooperativa dos Trabalhadores Assentados da Região de Porto Alegre - COOTAP (MARTINS, 2017).

No ano de 2002, realizou-se o $1^{\circ}$ Seminário do Arroz Ecológico, no qual os produtores que iniciaram o processo produtivo falaram sobre as suas experiências e os limites encontrados na produção. Esse evento configurou-se como um marco histórico para o desenvolvimento do processo de produção do arroz orgânico. No ano de 2004, durante o $3^{\circ}$ Seminário do Arroz Ecológico foi criado o GGAE, definindo-se assim os princípios e objetivos estratégicos, os eixos estruturantes e os recursos necessários para alcançar as metas estabelecidas para o grupo. Dessa forma, a partir da safra 2004/2005 instituiu-se o planejamento coletivo das lavouras de arroz, elemento esse fundamental para o sucesso da produção (MARTINS, 2017).

O GGAE se reúne, em média, quatro vezes ao longo do ciclo agrícola e conta com a participação de cerca de 60 pessoas, entre elas representantes de grupos de produtores e das cooperativas regionais, coordenadores da COOTAP e representantes da equipe de Certificação. Anteriormente, até o encerramento das atividades da Cooperativa de Trabalho em Serviços Técnicos (COPTEC), contava também com a presença de seus técnicos. Durante as reuniões são discutidas questões relativas ao processo de produção do arroz tais como o número de famílias e grupos envolvidos, a área plantada, a demanda de sementes e insumos para a safra, os distritos de irrigação, a certificação, os custos dos serviços realizados pelas cooperativas, os preços do arroz. Definem-se também as datas de capacitações e dias de campo e realiza-se o planejamento de recebimento da produção conforme os tipos de arroz e seu escopo e também se encaminha às 
cooperativas orientações comuns relacionadas ao processo de comercialização (MARTINS, 2017).

Além das reuniões do $\mathrm{GGAE}$, são realizados seminários regionais para avaliação da safra e para o planejamento da nova safra, nos quais participam todas as famílias envolvidas nos grupos de produção de cada região. A finalização desse processo de avaliação e planejamento ocorre nos Encontros Estaduais do Arroz Ecológico.

Também se considera importante chamar a atenção para que a expansão da produção do arroz orgânico que obteve apoio do Estado, através do financiamento da construção de estruturas de armazenagem e beneficiamento, fundamentais para propiciar este crescimento da produção (Figura 2), os quais atualmente encontram-se em fase de expansão (Figuras 3 e 4). De acordo com Campos e Medeiros (2014, p. 45): “Esse apoio ocorre, sobretudo na comercialização, mas também é significativo no financiamento das estruturas de armazenagem e beneficiamento, sem as quais não teria sido possível expandir a produção". Segundo as autoras, inicialmente os produtores não tinham acesso ao preço diferenciado do produto, pois tinham que entregar o arroz para ser armazenado em silos privados onde ele era misturado ao arroz convencional. A partir da obtenção de recursos de programas governamentais foi possível mudar essa situação e o arroz orgânico passou a ser armazenado em silos próprios sem o contato com o arroz convencional. 
Figura 2 - Unidade de Beneficiamento de Sementes da COTAP - Assentamento Lanceiros Negros, Eldorado do Sul, RS

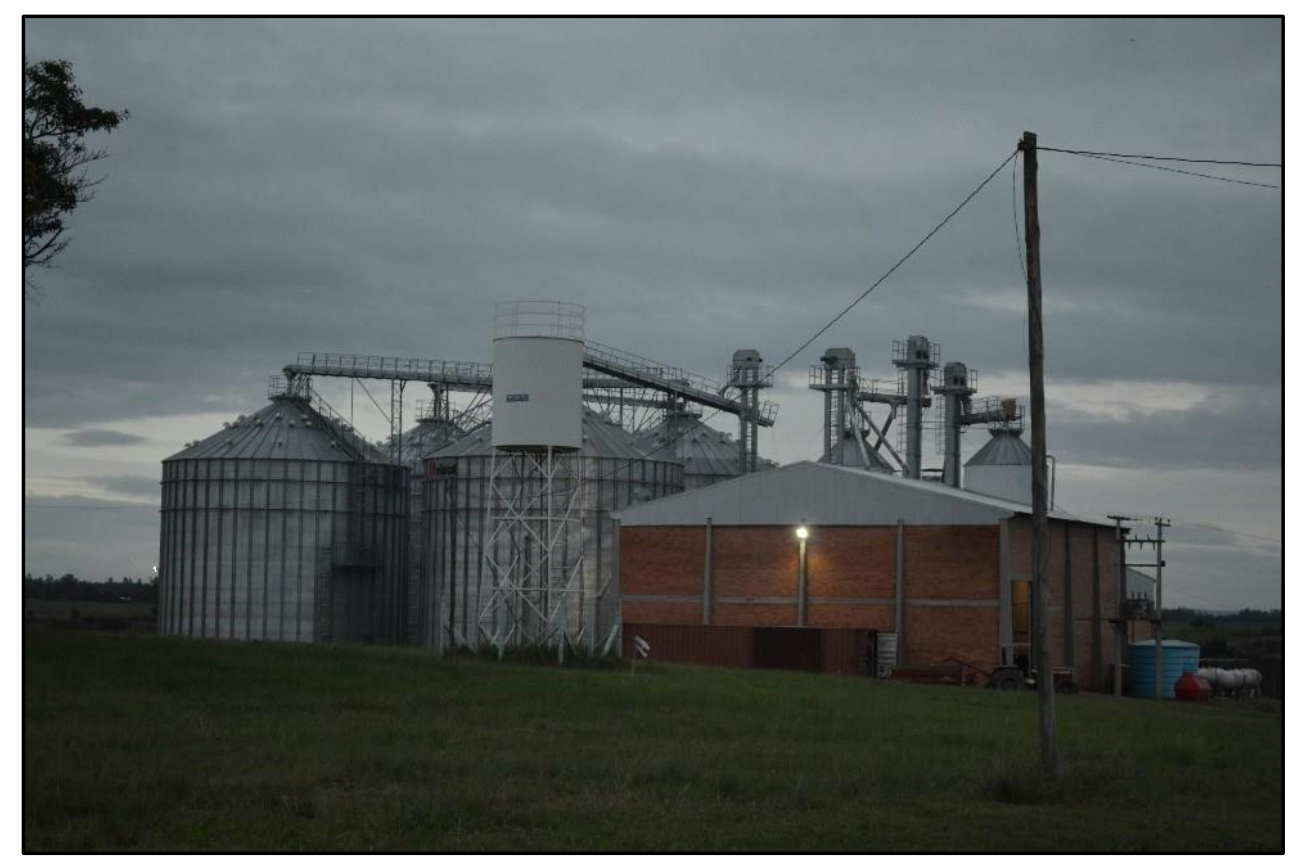

Fonte: Acervo particular dos autores (2017).

Figura 3 - Obras de ampliação da Unidade de Beneficiamento de Sementes da COTAP - Assentamento Lanceiros Negros, Eldorado do Sul, RS

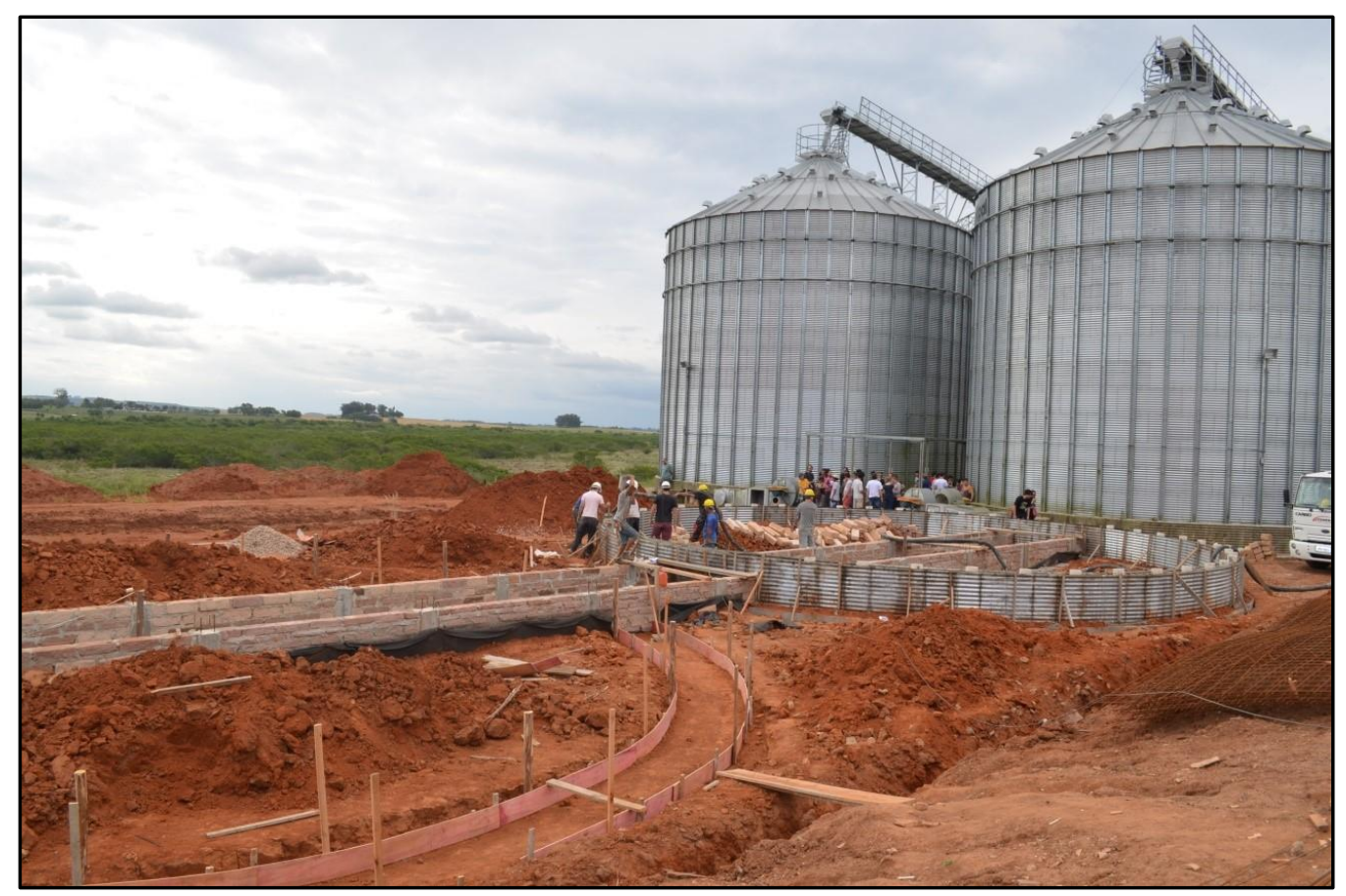

Fonte: Acervo particular dos autores (2018). 
Figura 4 - Projeto de ampliação da Unidade de Beneficiamento de Sementes da COTAP - Assentamento Lanceiros Negros, Eldorado do Sul, RS

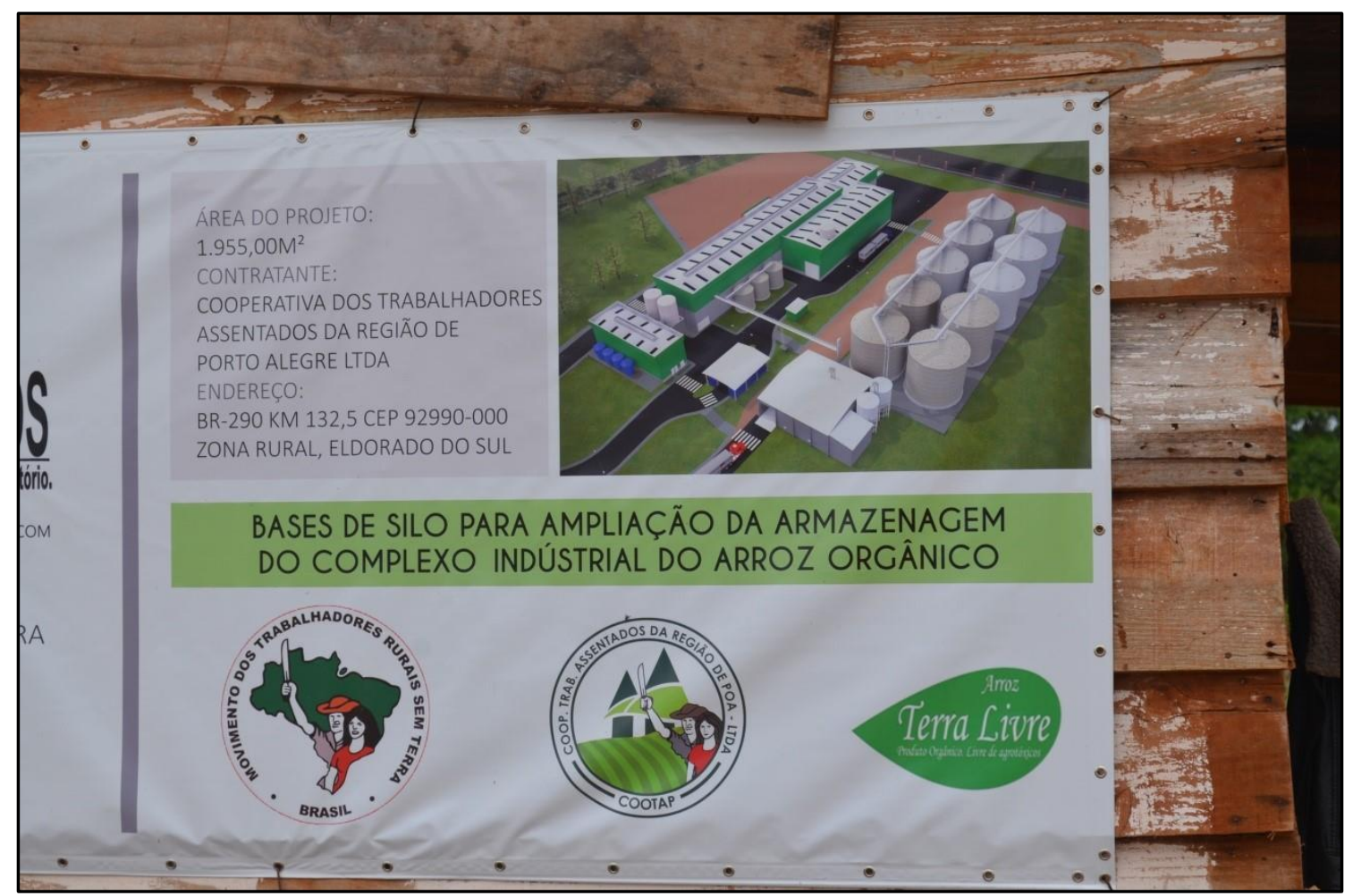

Fonte: Acervo particular dos autores (2018).

Outro fator importante para o desenvolvimento da produção do arroz orgânico nos assentamentos é citado por Medeiros et al (2013). Ao referir-se aos produtores de arroz orgânico de assentamentos da RMPA, destaca o fator geográfico como um elemento de forte influência, visto que a maior parte dos assentamentos produtores estão localizados próximos a capital do estado.

Esta proximidade reduz custos de transportes com os grandes centros consumidores bem como facilita a comunicação entre as famílias produtoras. Além disso, viabiliza uma maior articulação política e comercial com instituições de diferentes escalas governamentais pela facilidade das lideranças em participar de reuniões para se informar, negociar, participar de eventos onde divulgam e comercializam o produto (MEDEIROS et al, 2013, p. 13).

Contudo, a produção do arroz orgânico, além de estar localizada na Região Intermediária de Porto Alegre (Viamão, Nova Santa Rita, Eldorado do Sul, Charqueadas, São Jerônimo, Tapes, Arambaré), se expandiu para outras regiões do estado (Figura 5), sendo cultivada também em assentamentos localizados nas 
Regiões Intermediárias de Santa Maria (Santa Margarida do Sul), Uruguaiana (São Gabriel, Manoel Viana) e Pelotas (Canguçu).

Figura 5 - Mapa com os municípios com assentamentos produzindo arroz ecológico no RS

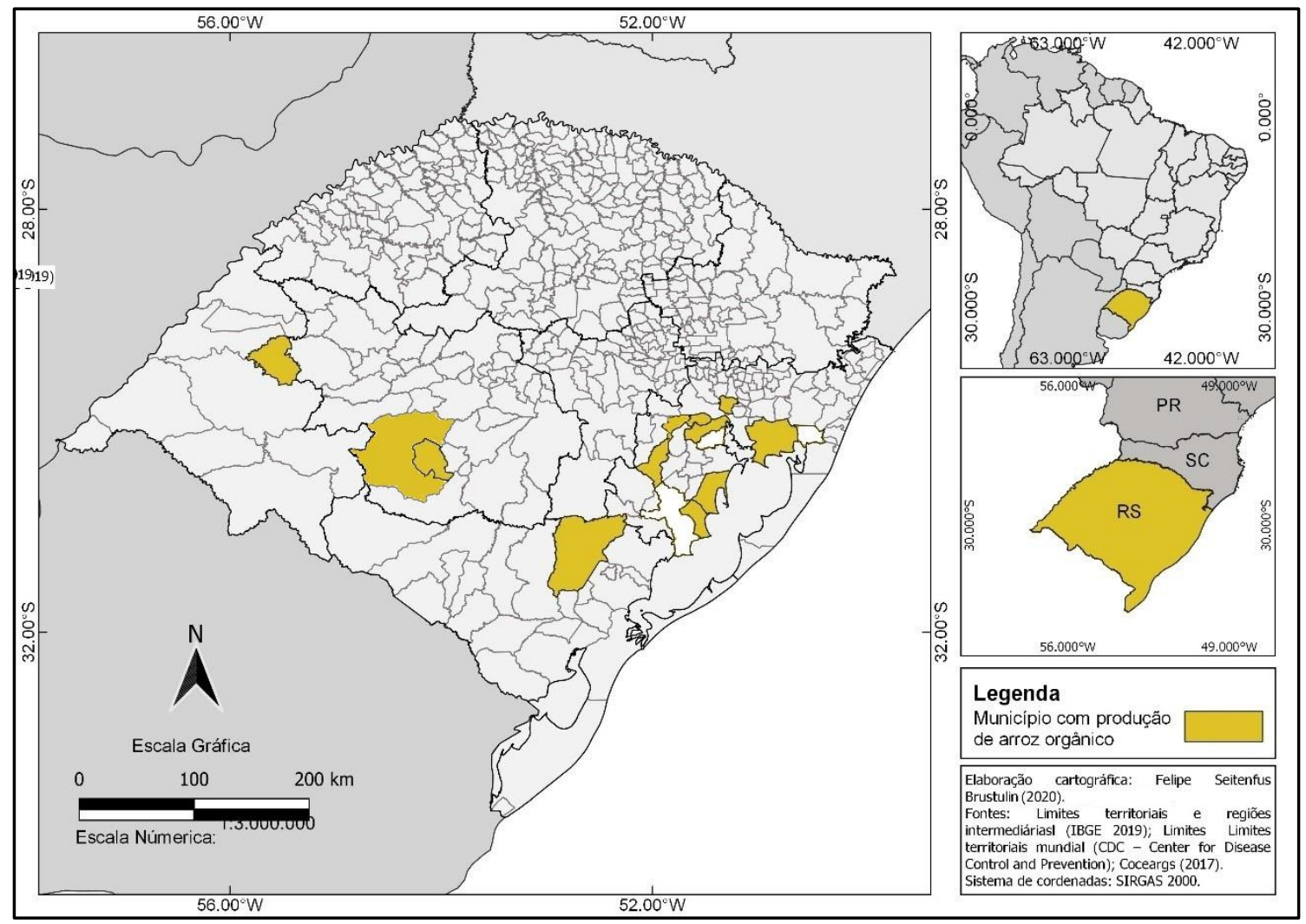

Fonte: Certificação Participativa da COCEARGS (2017).

Nesses casos é importante destacar que os produtores dos assentamentos dessas outras regiões estão fortemente integrados aos produtores da RMPA, tanto no que diz respeito à participação nas reuniões de planejamento da produção, quanto na utilização das estruturas de armazenagem e beneficiamento da produção. 


\section{A PRODUÇÃO E COMERCIALIZAÇÃO DO ARROZ ORGÂNICO DOS ASSENTAMENTOS RURAIS}

Ao analisamos experiências como a da produção do arroz orgânico nos assentamentos no Rio Grande do Sul, percebemos inúmeros benefícios desse tipo de produção. Entre eles, propiciar que os produtores produzam com menores custos e se insiram em um nicho de mercado promissor, além de ter ganhos com a saúde da família e a conservação ambiental do assentamento.

No entanto, para o êxito dessas experiências, é necessário que se tenha claro a importância da organização da produção. Nesse contexto, é importante destacar que a produção do arroz orgânico só se tornou possível para pequenos produtores através da organização coletiva dos assentados, que além da GGAE, se organizam em grupos de produção e cooperativas.

$\mathrm{Na}$ base da cadeia produtiva está o grupo de produtores que produz sementes. De acordo com informações da Certificação Participativa da COCEARGS, atualmente o grupo de produtores consegue atender cerca de $30 \%$ da demanda total da produção de sementes, cuja responsabilidade fica para um número determinado de famílias. Segundo informações de Martins (2017), o grau de exigência dessa produção fez com que somente poucas famílias se adaptassem a ela, que requer um acompanhamento rigoroso e uma grande dedicação por parte dos produtores. Essas sementes produzidas para o plantio são secadas, selecionadas, classificadas e armazenadas na Cooperativa dos Trabalhadores Assentados da Região de Porto Alegre (COOTAP), em sua Unidade de Beneficiamento de Sementes localizada no município de Eldorado do Sul.

De acordo com dados da Certificação Participativa da COCEARGS na safra de 2017/2018 foram plantados para esse fim um total de 128,8 hectares que geraram 12.577 sacas, com 628.850 quilos de sementes. 
As cooperativas, COOTAP, Cooperativa de Produção Agropecuária Nova Santa Rita (COOPAN), Cooperativa de Produção Agropecuária Assentados Tapes (COOPAT) e Cooperativa dos Produtores Orgânicos de Reforma Agrária de Viamão (COPERAV) são responsáveis pela secagem e armazenagem da produção. As cooperativas se reúnem para discutir o processo de recebimento da safra e as estratégias de armazenagem da produção, cuja coordenação é também do GGAE, o qual organiza atividades de capacitação para garantir qualidade da produção no momento de armazenagem. Quanto ao beneficiamento da produção, esse é realizado nas cooperativas COOTAP, COOPAN e COOPAT, onde se situam os Engenhos de Beneficiamento.

Outra informação a ser destacada se relaciona à produção de arroz orgânico da Campanha Gaúcha, que também é armazenada e beneficiada nas cooperativas citadas anteriormente, visto que as unidades de armazenamento que começaram a ser construídas na região da Campanha não foram finalizadas devido a falta de recursos e aos altos custos de operacionalização. Importante também chamar a atenção para o fato de que o transporte da produção requer um controle rigoroso, pois os grãos devem permanecer em temperaturas baixas de forma constante, o que nos Engenhos de Beneficiamento é feito com equipamentos especiais.

Soma-se a essas questões a necessidade de certificação imposta a produtos orgânicos. O arroz produzido pelos assentados é certificado através de duas formas: a Certificação por Auditoria, realizada pela IMO (Instituto do Mercado Ecológico) e a Certificação Participativa, desenvolvida pela COCEARGS.

A certificação foi uma exigência já colocada no ano de 2002 para a venda no varejo. Nesse primeiro momento, ela foi realizada através de auditoria pela IMO, no entanto apenas no ano de 2004, em uma nova auditoria, o certificado de orgânico foi concedido ao arroz ecológico. Atualmente a Certificação por Auditoria ainda continua sendo realizada pela IMO que certifica o escopo BRO e, com apoio da Empresa Ceres, certifica para o escopo CEE e NOP. De acordo com Martins (2017), a IMO realiza inspeções anuais, tendo certificado nesse ano cerca de 370 
famílias de produtores, além dos engenhos de arroz da COOPAN e COOPAT e os silos secadores da COOTAP. A certificação é realizada através de visitas da IMO, que inicialmente checa a documentação dos agricultores e cooperativas, no escritório da certificação, após faz uma escolha aleatória de $10 \%$ das famílias inclusas na certificação para a checagem dando preferência aos grupos mais novos e cooperativas com áreas maiores. Após a inspeção, a IMO emite uma nota, apresentando situações de conformidade. Por fim, é emitido um certificado geral em nome da COCEARGS, o qual possui uma lista com menção a lista de famílias presentes no processo, além de um certificado para cada unidade industrial com o nome dos produtos certificados (MARTINS, 2017).

A Certificação por Auditoria possui custos elevados, de acordo com Martins (2017), no ano de 2015, a inspeção da IMO custou a COOTAP em torno de $R \$ 55.000,00$, o que explica as críticas das organizações populares a esse tipo de certificação.

Já a Certificação Participativa teve início no ano de 2009 e trata-se de um mecanismo de controle interno a partir da organização local de produtores que realizam os procedimentos de inspeção e verificação. De acordo com a COCEARGS (2015, p.03), "o papel da Certificadora se limita em verificar a competência e credibilidade do trabalho do Sistema de Controle Interno". Esse processo de certificação possibilita garantir a participação nas feiras orgânicas, assim como garantir melhores preços junto aos programas governamentais de aquisição de alimentos (MARTINS, 2017).

No que se refere aos ganhos com a produção, Campos e Medeiros (2014) chamam a atenção é para o rendimento do arroz orgânico, o qual aparentemente parece pouco vantajoso, visto tem uma média de produção de 85 sacas por hectare se comparado ao arroz convencional cuja média é 150 sacas por hectare. Contudo, as autoras colocam que os custos de produção do arroz orgânico são três vezes menores que o do convencional, de formas que o rendimento econômico da 
produção orgânica se torna maior. De acordo com informações da Certificação Participativa da COCEARGS os custos de produção, a nível de produtor é bem menor do que no convencional, enquanto no convencional os custos são de aproximadamente 187 sacas por hectare, no orgânico este custo desce para 70 sacas por hectare. Levando em conta que a média colhida no convencional no ano de 2018 foi de 158 sacas por hectare, no orgânico a média foi de aproximadamente 100 sacas, assim, na relação custo de produção/produtividade, enquanto no orgânico teve uma sobra de 30 sacas, o convencional teve um déficit de quase 30 sacas. O técnico da Certificação Participativa da COCEARGS explica que o que diminui significantemente esta margem é na armazenagem, aonde no orgânico as perdas são bem maiores que no convencional, que aplica diversos produtos químicos para controles de insetos e conservação dos grãos enquanto no orgânico não existe esta possibilidade, isto acrescido ao fato de que as unidades de armazenagem e beneficiamento precisam ser certificadas, o que é um processo é relativamente caro.

Além disso, existe também o preço diferenciado dos produtos orgânicos que podem ser até 30\% superiores ao preço dos produtos convencionais. Nesse caso, é necessário esclarecer que este acréscimo de 30\% em relação ao arroz convencional se dá nas vendas institucionais, o que atualmente nem sempre é garantido já que muitas prefeituras estão trabalhando com chamada pública para merenda escolar tendo como base o "melhor preço". Para as vendas no varejo, o preço praticado não chega a atingir esta margem, a média fica em torno de $20 \%$ a $25 \%$ superior ao valor do convencional. A cooperativa no momento da compra do produto do agricultor, verifica no site de órgãos oficiais, o valor da saca (em grão) praticado no dia, e em cima deste valor, acrescenta $15 \%$, tendo o produto orgânico pago aos agricultores esta valorização frente o produto convencional. Já a cooperativa fica com $5 \%$ a $10 \%$ do valor incorporado no momento da comercialização, essa margem, serve para pagar despesas com pessoal, escritório, fomentar a próxima safra. O fomento da próxima safra se dá no sentido da 
aquisição de produtos com fornecedores (semente, adubo orgânico, diesel, etc), pois como a maioria dos fornecedores trabalham com um prazo pequeno, a cooperativa compra estes insumos, e repassa aos produtores, para que estes paguem somente na safra. Os custos de produção por hectare da safra 2017/2018 do arroz orgânico podem ser observados no Quadro 1.

Quadro 1 - Custo de produção do Arroz Orgânico (ha) - Safra 2017/2018

\begin{tabular}{|lc|}
\hline \multicolumn{1}{|c|}{ Itens } & Valor (R\$) \\
\hline Manutenção Bomba e Energia Elétrica & 125,91 \\
Manutenção Geral e dos Implementos & 352,54 \\
Limpeza dos Canais & 210,54 \\
Sementes de Arroz & 374,89 \\
Adubação Orgânica & 94,46 \\
Serviços de Máquinas e Transporte até o Silo & $1.539,13$ \\
Mão de Obra dos Associados & 768,68 \\
Mão de Obra Contratada & 123,62 \\
Impostos/Taxas/Custo Certificação & 71,42 \\
\hline Total & $3.661,19$ \\
\hline Produtividade Copan (sacos) & 95 \\
Custo por Hectare em Sacos & 38,54 \\
\hline Preço Médio Recebido por Saco & 47,00 \\
\hline
\end{tabular}

Fonte: COPAN (março de 2018).

Assim, é importante chamar a atenção para que o valor superior desse tipo de produção se dá entre outras características devido a intensidade do trabalho humano na produção orgânica ser maior pela necessidade de uma constante vigilância na produção por parte do produtor.

A comercialização da produção acontece em várias escalas, desde a comercialização direta nas feiras ecológicas na cidade de Porto Alegre e Região Metropolitana até a exportação para outros continentes, no entanto grande parte da produção é entregue para merenda escolar através do Programa Nacional de Alimentação Escolar (PNAE). 
Tabela 2 - Comercialização de Arroz Orgânico COOTAP

\begin{tabular}{lcccc}
\hline \multicolumn{1}{c}{ Fonte } & Arroz polido & \% & Parabolizado & $\%$ \\
\hline PNAE* & 696.060 & 28,5 & 107.000 & 9,8 \\
PAA - Doação** & 240.064 & 9,8 & 0 & 0 \\
PAA - Estoque & 1.475 .982 & 60,5 & 983.988 & 90,2 \\
Redes/Feiras & 25.000 & 1 & 0 & 0 \\
\hline Total em kg & 2.437 .106 & & 1.090 .988 & \\
\hline Total em Sacas & 84.038 & & 41.310 & \\
\hline
\end{tabular}

Fonte: Martins (2017).

* Programa Nacional de Alimentação Escolar.

** Programa de Aquisição de Alimentos.

Conforme a Tabela 2, é possível observar pelos dados que a maior parte do arroz orgânico está direcionado para as vendas institucionais, como o PNAE já mencionado, que se destina à merenda escolar.

Tabela 3 - Arroz Comercializado no PAA - Série Histórica

\begin{tabular}{ccccc}
\hline Ano & Pessoas beneficiadas & Preço/Kg & Quantidade (kg) & Valor Total (R\$) \\
\hline 2010 & 288 & 1,88 & 16.418 & $30.865,84$ \\
2011 & 21.680 & 1,7 & 93.348 & $158.691,60$ \\
2012 & 5.766 & 2,14 & 48.240 & $103.233,60$ \\
2013 & 5.681 & 2,14 & 75.528 & $161.629,92$ \\
2014 & 27.026 & 2,32 & 331.296 & $768.606,72$ \\
2015 & 3.724 & 2,43 & 103.760 & $252.136,80$ \\
2016 & 67.749 & 2,7 & 148.655 & $401.368,50$ \\
$2017^{*}$ & 44.082 & 0 & 0 & 0 \\
$2018^{* *}$ & 0 & 0 & 0 & 0 \\
\hline \multicolumn{7}{c}{} & 175.996 & & & $1.876 .532,98$ \\
\hline
\end{tabular}

Fonte: COOTAP (2018).

* Houve PAA mas o arroz não entrou.

** Não houveram projetos do PAA.

Já a tabela 3, mostra a série histórica da comercialização de Arroz no PAA, que visa a compra de alimentos produzidos pela agricultura familiar e é destinado pessoas em situação de insegurança alimentar e nutricional, atendidas por instituições públicas, filantrópicas e de ensino. Assim, ao comparamos as tabelas 2 e 3, percebemos a importância do PAA nas comercializações institucionais e a necessidade desses produtores em buscar novos mercados consumidores, já que 
de acordo com as informações no ano de 2017 houve PAA, mas o arroz não entrou no Programa e no ano de 2018 não houveram projetos do PAA.

A maior fatia do mercado consumidor do arroz orgânico está no centro e centro-oeste do país. São Paulo foi um grande consumidor desta produção, no entanto por decisão política e falta de recursos as compras foram canceladas. No estado do Rio Grande do Sul parte significativa da produção comercializada, foi destinada aos presídios estaduais.

Mas é importante ressaltar que o arroz também conquistou os mercados internacionais, tendo sido comercializado através de uma parceria com o governo da Venezuela no ano de 2017, a qual possibilitou que grande parte do arroz da safra passada que estava estocado fosse comercializado. Recentemente o produto também tem sido exportado para Alemanha.

Contudo, mesmo com o forte da comercialização ainda sendo os mercados institucionais, cresce também a comercialização em mercados convencionais, como Armazéns do Campo e lojas de produtos orgânicos e naturais.

\section{CONSIDERAÇÕES FINAIS}

A evolução e a crescente importância da produção do arroz orgânico no Rio Grande do Sul, que teve início na Região Metropolitana de Porto Alegre e que se expandiu para outras regiões do estado, demonstram claramente o papel transformador que essa produção teve nos assentamentos e na vida dos agricultores assentados. Experiências como esta que trazem benefícios tanto aos produtores, como aos consumidores e ao meio ambiente, devem ser multiplicadas e estimuladas, sobretudo se for considerada a crescente ampliação do mercado consumidor.

Nesse contexto, entende-se a pertinência de analisar a produção do arroz orgânico no Rio Grande do Sul, por ser ela a experiência que se tornou referência na produção de orgânicos no Brasil e na América Latina. 
Os benefícios econômicos que a produção de arroz orgânico tem trazido para os assentamentos e para as famílias assentadas produtoras são visíveis. Suas conquistas vão além do melhor viver, ganharam também o respeito da população local, conquistaram mercados, deram visibilidade à experiência em nível nacional, demonstraram que esta conquista é um processo que ainda não está finalizado e necessariamente precisa ser recriado para assim seguir o rumo da sustentabilidade. Portanto, é necessário ressaltar os impactos positivos dessa produção, enquanto experiência que pode potencializar o desenvolvimento local e regional.

Outro ponto importante que deve ser destacado nesta análise é o fato de que essa experiência transformou a forma de produzir arroz, ao mostrar que é possível ter produtividade expressiva sem o uso de agrotóxicos. Ao reunir agricultores assentados com pequenas propriedades (entre 12 e 40 ha), desmistifica a tese de que a produção de arroz só é viável em médias e grandes propriedades. Esta é uma experiência de significativa importância, pois ao participarem de todo o processo produtivo, as famílias agricultoras rompem não apenas com um padrão de produção agrícola convencional, mas constroem novas alternativas de inclusão socioeconômicas para agricultores que não conseguiram adaptar-se ao mercado de produção convencional e que historicamente já haviam sido excluídos do processo produtivo.

A produção de arroz orgânico é um importante elemento de fixação do homem no campo, trazendo grandes contribuições para o desenvolvimento socioeconômico. Além disso fortaleceu a relação urbano rural ao colocar também como objetivo produzir alimentos saudáveis para serem consumidos nas cidades. Esta é a alternativa de produção que vem ao encontro da construção de uma nova sociedade mais consciente, mais participativa e mais eficaz em suas ações. 


\section{REFERÊNCIAS}

ALTIERI, M. Agroecologia: bases científicas para uma agricultura sustentável. 3.ed. ver. Ampl. São Paulo, Rio de Janeiro: Expressão Popular, AS-PTA, 2012.

CAMPOS, C. S. S.; MEDEIROS, R. M. V. Avanços e contradições da produção orgânica nos assentamentos - o caso do arroz na Região Metropolitana de Porto Alegre. In: MEDEIROS, R. M. V.; LINDNER, M. (Org.). Assentamentos rurais, território, produção: novas alternativas no Rio Grande do Sul. Porto Alegre, RS: NEAG/UFRGS, Evangraf. 2014. p. 41-58.

CANDIOTTO, L. Z. P.; CARRIJO, B. R.; OLIVEIRA, J. A. de. A agroecologia e as agroflorestas no contexto de uma agricultura sustentável. In: ALVES, A. F.; CARRIJO, B. R.; CANDIOTTO, L. Z. P. (Org.). Desenvolvimento territorial e agroecologia. São Paulo: Expressão Popular, 2008. p. 213-232.

COCEARGS. Manual de Trabalho do Sistema Interno de Controle. Porto Alegre, RS: Mimeo, 2015.

FERNANDES, B. M. A formação do MST no Brasil. Petrópolis, RJ: Vozes, 2000.

INCRA. História da Reforma Agrária. 2020-a. Disponível em: http://www.incra.gov.br/pt/reforma-agraria/62-reforma-agraria/221-historia-da-reformaagraria.html. Acesso em: 10 de jan. de 2020.

INCRA. Projetos de Reforma Agrária Conforme Fases de Implementação. 2020-b. Disponível em: http://www.incra.gov.br/sites/default/files/uploads/reforma-agraria/questaoagraria/reforma-agraria/projetos_criados-geral.pdf. Acesso em: 26 de mar. 2020.

MARTINS, A. F. G. A produção ecológica de arroz nos assentamentos da região metropolitana de Porto Alegre: apropriação do espaço geográfico como território de resistência ativa e emancipação. 2017. 296p. Tese (Doutorado em Geografia) - Universidade Federal do Rio Grande do Sul, Porto Alegre.

MEDEIROS, R. M. V. et al. Cadeia produtiva do arroz ecológico nos assentamentos da Região Metropolitana de Porto Alegre/RS: Análise territorial e ambiental. 2013. 38p. Relatório (Pesquisa) - Universidade Federal do Rio Grande do Sul - NEAG/UFRGS, Porto Alegre.

MENEGON, L. et al. Produção de arroz agroecológico em assentamentos de reforma agrária no entorno de Porto Alegre. Revista Brasileira de Agroecologia, v. 4, n. 2, 2009.

SILVA, L. O. Terras devolutas e latifúndio: efeitos da Lei de Terras 1850. Campinas, SP: Editora da UNICAMP, 1996. 


\section{1 - Michele Lindner:}

Doutorado em Geografia, Professora do Departamento de Geografia e Programa de Pós-

Graduação em Geografia UFRGS

https://orcid.org/0000-0002-1823-0811•michele.lindner@ufrgs.br

Contribuição: Pesquisa, elaboração e revisão do artigo

\section{2 - Rosa Maria Vieira Medeiros:}

Doutorado em Geografia, Professora do Departamento de Geografia e Programa de PósGraduação em Geografia UFRGS

https://orcid.org/0000-0001-7189-1902•rmvmedeiros@ufrgs.br

Contribuição: Pesquisa e revisão do artigo

\section{Como citar este artigo}

LINDNER, M.; MEDEIROS, R. M. V. Produção de arroz orgânico em assentamentos rurais no Rio Grande do Sul: práticas de organização coletiva e sua contribuição para a fixação do homem no campo. Geografia Ensino \& Pesquisa, Santa Maria, v.25, e36, p. 01-23, 2021. DOI 10.5902/2236499464300. Disponível em: https://doi.org/10.5902/2236499464300. Acesso em: dia mês abreviado. ano. 